NASA Technical Memorandum 106409

AIAA-93-4321

\title{
Instability Modes Excited by Natural Screech Tones in a Supersonic Rectangular Jet
}

Ganesh Raman

Sverdrup Technology, Inc.

Lewis Research Center Group

Brook Park, Ohio

and

Edward J. Rice

National Aeronautics and Space Administration

Lewis Research Center

Cleveland, Ohio

Prepared for the

15th AIAA Aeroacoustics Conference

sponsored by the American Institute of Aeronautics and Astronautics

Long Beach, California, October 25-27, 1993 


\author{
AIAA-93-4321 \\ Instability Modes Excited by Natural \\ Screech Tones in a Supersonic \\ Rectangular Jet \\ G. Raman \\ Sverdrup Technology, Inc. \\ Lewis Research Center Group \\ Brook Park, OH \\ and \\ E.J. Rice \\ NASA Lewis Research Center \\ Cleveland, $\mathrm{OH}$
}

\author{
15th AIAA \\ Aeroacoustics Conference \\ October 25-27, 1993 / Long Beach, CA
}




\title{
INSTABILITY MODES EXCITED BY NATURAL SCREECH TONES IN A SUPERSONIC RECTANGULAR JET
}

\author{
Ganesh Raman* \\ Sverdrup Technology, Inc. \\ Lewis Research Center Group \\ Brook Park, Ohio 44142 \\ and \\ Edward J. Rice ${ }^{* *}$ \\ National Aeronautics and Space Administration \\ Lewis Research Center \\ Cleveland, Ohio 44135
}

\begin{abstract}
The evolution of hydrodynamic instability modes selfexcited by harmonically related natural screech tones was experimentally investigated. A convergent rectangular nozzle with an aspect ratio of 9.63 was used to produce a supersonic shock containing jet. Measurements in the flow-field were made using standard hot-film probes positioned only in the subsonic (outer) portions of the flow. The hydrodynamic instability mode observed in the shear layer at the screech frequency was observed to be antisymmetric (sinuous) about the smaller dimension of the jet, whereas its harmonic was observed to be symmetric (varicose). In addition the nearfield noise measurements indicated that the radiated screech tone noise was out-of-phase on either side of the small jet dimension whereas its harmonic was in-phase over the same region. To our knowledge such an observation on the nature of the harmonic has thus far gone unreported and therefore, is the focus of the present work. The hydrodynamic instability modes occurring at the screech frequency and its harmonic satisfied the conditions for resonance. Detailed measurements of the coherent wave evolution in the streamwise and
\end{abstract}

spanwise directions indicated that strong spanwise variations were present beyond $\mathrm{x} / \mathrm{h}=8$. Details of the screech noise radiated by the coherent instability modes are also presented in this paper.

\section{NOMENCLATURE}

$A_{d}$ jet exit cross-sectional area
$A_{j}$ fully expanded jet cross-sectional area
$a$ speed of sound
$b \quad$ larger dimension of rectangular nozzle
$c$ axial phase velocity
c/a dimensionless axial phase velocity
$c / U_{j}$ dimensionless axial phase velocity
$D_{c}$ equivalent jet diameter
$f \quad$ frequency
$h$ smaller dimension of rectangular nozzle
$h_{j}$ fully expanded smaller jet dimension
$M_{\text {Mach number }}$ Mach
$M_{j}$ fully expanded jet Mach number
$P_{a}$ ambient pressure
$P_{t}$ pitot pressure
$P_{t o}$ plenum pressure
$\mathrm{Re}$ Reynolds number

"Research Engineer, Member AIAA

**Lewis Distinguished Research Associate, Retired, Member AIAA 
St Strouhal number

$s$ aspect ratio $(b / h)$

$\mathrm{T}_{0}$ jet stagnation temperature

$\mathrm{T}_{s}$ jet static temperature

th dimensionless nozzle lip thickness

$\mathrm{U}$ mean axial velocity

$\mathrm{U}_{\mathrm{j}}$ fully expanded mean axial velocity

ũ coherent component of velocity

$\tilde{\mathrm{u}}_{0}$ coherent component of velocity at $\mathrm{x} / \mathrm{h}=1.76$

$\tilde{\mathrm{u}}_{\mathrm{f}}$ coherent component of velocity at the fundamental screech frequency

$\tilde{\mathrm{u}}_{2 f}$ coherent component of velocity at the harmonic of the screech frequency

$x$ axial distance (see Fig. 1(a))

y transverse distance (see Fig. 1(a))

$\mathrm{y}_{0.4}$ transverse coordinate of the $\mathrm{M}=0.4$ location

$\mathrm{z}$ vertical distance (see Fig. 1(a))

$\alpha_{I}$ axial wavenumber

$\gamma$ ratio of specific heats of gases

$\theta$ azimuthal angle (see Fig. 1(b))

$\lambda$ axial wavelength

$\omega$ frequency parameter $(2 \pi f)$

\section{INTRODUCTION}

The phenomenon of screech has been described by Powell ${ }^{1}$ as the result of a self-sustaining feedback loop. In the shear layer of a supersonic jet, hydrodynamic instabilities are triggered and some of these are amplified with an increase in downstream distance. Beyond the third shock cell these growing instabilities have enough energy to interact with the shocks to produce an intense tone, known as screech. This will be referred to as the inner part of the screech loop. In the outer part of the screech loop, the screech tone produced as described earlier propagates upstream (feedback) to the jet exit and excites hydrodynamic instabilities in the initial shear layer, thus closing the loop. It should be recognized that the above explanation is a very simplistic one. In reality the phenomenon is far more complex. For example there are multiple screech sources (Powell ${ }^{1}$ ) in the region between the 3rd and 7th shocks, and sometimes no two cycles of screech are exactly repeatable (Davies and Oldfield ${ }^{2.3}$ ) and further, when the screech tone propagating upstream eventually reaches the nozzle lip, the pressure wave is scattered by the lip, creating a broad spectrum of wavelengths in the process (Morkovin, ${ }^{4}$ Rogler and Reshotko ${ }^{5}$ ). It is this broad spectrum that permits a coupling between the acoustic and hydrodynamic waves, thus producing a resonant loop.

There have been several investigations on screech tones in jets. Screech tones from supersonic underexpanded jets were investigated by Hammitt, ${ }^{6}$ Glass, ${ }^{7}$ Krothapalli et al., ${ }^{8}$ Gutmark et al., ${ }^{9}$ and Rice and Taghavi, ${ }^{10}$ and a comprehensive review of jet aeroacoustics was provided by Seiner. ${ }^{11}$ However, most of the measurements reported in these papers have focused on the outer part of the screech loop (nearfield acoustics) or on the flowfield far downstream. Morrison and McLaughlin ${ }^{12}$ and Lepicovsky et al. $^{13}$ investigated hydrodynamic instability modes in supersonic ideally expanded circular jets. However, under such operating conditions, shocks and screech are minimized or absent. With the exception of the work by $\mathrm{Hu}$ and McLaughlin ${ }^{14}$ on a circular jet, it appears that most of the other published work has focused on the outer part of the screech loop (feedback). To our knowledge there are no detailed measurements on the instability modes in a supersonic rectangular jet excited by its own screech tones, and that is the objective of the present work. The present work focuses on the curious phenomenon of the screech mode (f) occurring in the antisymmetric mode and its harmonic (2f) occurring in the symmetric mode. It appears that such an observation has gone unreported before. On close examination of the data of Gutmark et al. ${ }^{9}$ it is apparent that such a trend was visible in their data too. However, this aspect of the screech tone and its harmonic was not highlighted since their paper had a different focus. It is very important to note that since this event was recorded in two independent and vastly different experimental facilities, the possibility of this observation being facility-dependent is highly improbable.

Several papers have addressed the role of coherent structures in the production of noise. ${ }^{15-22}$ However, the connection between the two is far from being fully understood. For example, although there exist approximate expressions $\left(\mathrm{Tam}^{23}\right)$ that can predict the frequency of the screech tone, there are none that can predict the amplitude of the tone. An understanding of the connection between the hydrodynamic instability waves in the shear layer and the acoustic modes (in the nearfield) would be a first step towards achieving this goal. The task that is attempted in the present work is difficult but important because, to our knowledge, there is neither a stability analysis 
nor a detailed set of data on the hydrodynamic instability modes in a rectangular supersonic jet containing shock cells and screech tones. In addition there are severe difficulties in performing a direct numerical simulation of acoustics with strong shocks in the system $\left(\mathrm{Cain}^{24}\right)$. Knowledge of the relationship between coherent velocity fluctuations in the shear layer and its radiated noise could be useful for reducing jet noise via changes in the jet coherent structure and in addition would aid in calculating such flows.

\section{EXPERIMENTAL DETAILS}

\subsection{Supersonic Jet Facility}

The experimental set-up included a $76 \mathrm{~cm}$ diameter plenum tank which had acoustic treatment and flow conditioning. Attached to the plenum was a nozzle that transitioned smoothly from a $5 \mathrm{~cm}$ circular crosssection to a rectangular geometry. Figure 1(a) is a schematic of the supersonic jet facility. Figure 1(b) is a photograph of the rectangular nozzle with three hotfilm probes. The nozzle and the end of the plenum tank were covered with acoustically absorbent material. The nozzle exit rectangular dimensions were $7.37 \mathrm{~mm}$ and $71 \mathrm{~mm}$ with the larger dimension in the vertical $(\mathrm{Z})$ direction. The nozzle lip thickness normalized by the smaller dimension of the nozzle was 0.25 . It has been shown by Ponton and Seiner ${ }^{25}$ that this parameter has a significant effect on the amplitude and frequency of certain screech modes. For a nozzle with a thicker lip, the upstream propagating screech tone can reflect off the increased nozzle lip area and excite the jet differently. The plenum tank pressure was maintained constant to within $0.25 \%$ of the set point using automatic electronically controlled valves. Typical jet operating conditions are given in Table I.

\subsection{Measurement Techniques}

Measurements of the flow field were made using standard hot-film probes. The hot-films were positioned only in the subsonic portions of the flow. Relative phase measurements were made with the hotfilm probe moved in the vertical(z) and axial(x) directions and its signal referenced to that of a reference probe. A total pressure probe $(0.8 \mathrm{~mm}$ o.d.) was used to survey the flowfield. A $0.64 \mathrm{~cm}$ (B \& K) microphone was used to obtain sound pressure levels and spectra. The $0.64 \mathrm{~cm}$ microphones were omnidirectional (according to manufacturer specifications) within $\pm 1 \mathrm{~dB}$ up to $10 \mathrm{KHz}$ and within $\pm 3 \mathrm{~dB}$ up to $20 \mathrm{KHz}$.

\subsection{Flow Visualization}

A focusing schlieren system similar to the one described by Weinstein ${ }^{26}$ was used with steady light for continuous monitoring of the jet during the measurements. This system was described previously by Rice and Raman. ${ }^{27}$ The strobed schlieren system was operated in a swept phase mode to produce motion pictures of the flapping mode of the jet. With the focusing schlieren system one could focus on any part of the flow and separate details from the back, front and the center of the jet. In the present work the center of the jet was in focus.

\section{RESULTS AND DISCUSSION}

The general characteristics of the rectangular underexpanded jet $\left(1.1<\mathrm{M}_{\mathrm{j}}<1.8\right)$ will be discussed first. These include shock cell location and spacing, screech tone frequency and amplitude, and the flapping instability mode. Following the general discussion, the focus will be on the $\mathrm{M}_{\mathrm{j}}=1.44$ case. For this case measurements in the inner and outer parts of the feedback loop will be compared. Observations on the hydrodynamic instability modes will be made and the mutual interaction of these modes will then be discussed using measured wavenumbers and phase velocities. Finally the details of the coherent instability wave evolution in the streamwise and spanwise directions and its radiated noise will be presented. It should be noted that the following terms will be used synonymously in this paper: "antisymmetric", "sinuous", and "flapping". In addition "symmetric", "varicose" and "nonflapping" will also be used synonymously.

\subsection{Characteristics of the Screech Tone}

The complex three dimensional shock cell structure was visualized using a focusing schlieren system. Figure 2(a-j) shows long time exposure stills taken using continuous lighting. The shock locations are indicated on the photographs for the $\mathrm{M}_{\mathrm{j}}=1.44$ case. The faint vertical lines are the grid lines of the focusing schlieren system. The sensitivity is highest in the direction normal to the grid lines. Both planes 
of the rectangular jet are shown. Figure 3(a-d) shows single frames from the swept phase strobed video sequence for the various Mach numbers. The phase synchronization technique as well as the operation of the strobed schlieren system was described previously by Rice and Raman. ${ }^{27}$ For the $\mathrm{M}_{\mathrm{j}}=1.1$ case (Figure 3(a)) the screech tone amplitude was very low and no periodic waves were observed. The other three Mach number cases displayed large wave amplitudes that were excited by the natural screech tone. There is an increase in the instability wavelength with an increase in $\mathrm{M}_{\mathrm{j}}$. It is this flapping motion (antisymmetric or sinuous mode) that is responsible for the enhanced mixing of the screech excited jet. A detailed documentation and discussion of this instability mode is presented in the next few sections.

A pair of microphones located behind the nozzle lip on either side of the smaller dimension of the nozzle were used to obtain the data presented in Figure 4(ac). Figure 4(a) shows a plot of Strouhal number $\left(\mathrm{fh}_{\mathrm{j}}\right.$ $\mathrm{U}_{\mathrm{j}}$ ) of the screech tone versus fully expanded Mach number. As the Mach number increases, the Strouhal number of the screech tone decreases. This is due to the increase in shock cell spacing with Mach number which causes a decrease in the screech frequency. The change in the fully expanded dimension, $\mathrm{h}_{\mathrm{j}}$, is small compared to the change in velocity, $U_{j}$, with increase in Mach number. In the calculation of the screech Strouhal number the measured frequency was used in conjunction with the fully expanded jet velocity, $\mathrm{U}_{\mathrm{j}}$, and the fully expanded jet dimension, $\mathrm{h}_{\mathrm{j}}$ . For the calculation of the full expanded jet velocity, $\mathrm{U}_{\mathrm{j}}$, the speed of sound was calculated at each Mach number taking into account the changes in temperature. The fully expanded jet dimension, $h_{j}$, was obtained using Tam's ${ }^{23}$ relationship.

$$
\frac{h_{j}}{h}=\left[\left(\frac{A_{j}}{A_{d}}\right)-1\right]\left[\frac{b}{h+b}\right]+1
$$

where $A_{j} / A_{d}$ is obtained from the one dimensional gas dynamics equation given below and, the subscript " $d$ " refers to conditions at the jet exit.

In Figure 4(a) Tam's ${ }^{23}$ analytic solution of the screech Strouhal number versus Mach number is also shown for comparison. However, Tam's ${ }^{23}$ solution is based on an assumed phase velocity $\left(\mathrm{c} / \mathrm{U}_{\mathrm{j}}\right)$ of 0.7 for the

$$
\left(\frac{A_{j}}{A_{d}}\right)^{2}=\frac{1}{M_{j}^{2}}\left[\frac{\left(1+\frac{(\gamma-1)}{2} M_{j}^{2}\right)}{\left(1+\frac{(\gamma-1)}{2}\right)}\right]^{\frac{(\gamma+1)}{(\gamma-1)}}
$$

instability wave. The measured phase velocity of the screech mode in the present experiment is about 0.542 (Table II). It is expected that the use of the measured phase velocity, in conjunction with Tam's $\mathrm{s}^{22}$ theory will produce better agreement.

Figure 4(b) shows a plot of the screech tone amplitude measured at the nozzle lip versus the fully expanded Mach number. The screech amplitudes are high $(\sim 155-158 \mathrm{~dB})$ over the Mach number range from 1.2 to 1.6. The amplitudes of the harmonic of the screech tone are much lower $(\sim 145 \mathrm{~dB})$ over the same Mach number range.

Figure 4(c) shows a plot of the phase difference between two microphones placed on either side of the jet. The phase difference at the screech tone frequency is about 180 degrees for the entire Mach number range. However, for the harmonic of the screech frequency the phase difference is about 0 for the entire Mach number range. Since the amplitude of the screech tone is much higher than that of its harmonic the antisymmetric (flapping) mode appears to be the dominant mode over the entire Mach number range. It has been shown by Powell ${ }^{1}$ and by Hammitt ${ }^{6}$ that two-dimensional jets do not have discontinuous frequency jumps or the "multi-mode" structure. The findings of the present work are consistent with their observations. In addition, data from axisymmetric convergent divergent nozzles with design Mach numbers of 1.5 and 2.0 indicates that only a single mode structure exists $\left(\right.$ Seiner $\left.^{11}\right)$. Therefore, the staging of screech tones or the "multimodal" behavior seems to be present only for the case of the sonic axisymmetric nozzle.

Figure 4(d) shows the shock spacing versus fully expanded Mach number. The computational results of Morris et al. ${ }^{28}$ and the analytical result of $\mathrm{Tam}^{23}$ are shown for comparison. It should be pointed out that the computation of Morris et al. ${ }^{28}$ is for an aspect ratio $(\mathrm{b} / \mathrm{h})$ of 5.83 whereas the experimental data is from a nozzle with $a b / h$ of 9.63 . Despite the differences in aspect ratio between the computation 
and the experiment, the agreement seems reasonable.

\subsection{Evolution of the Mean Flowfield}

Figure 5 shows the normalized jet pitot pressure measured on the jet's centerline. The peaks and valleys are due to the shock/expansion process. Cross-sections of locations marked (a-e) in Figure 5 are described in Figure 6(a-e). In Figure 6, the outer most curve is the $P_{t} / P_{t o}=0.003$ contour. The values of the innermost contours in Figures 6 (a-e) are indicated on the figure. Note that $\mathrm{x} / \mathrm{h}=1$ corresponds to a valley in Figure 5 , whereas $x / h=5$ corresponds to a peak. Therefore the value of the innermost contour is higher at $\mathrm{x} / \mathrm{h}=5$ than at $\mathrm{x} / \mathrm{h}=$ 1 and this is clear from Figure $6(a, b)$. For the first three locations the total pressure probe passes through a complex shock-cell system and therefore the data should be viewed as being qualitative. Further downstream the flow is subsonic everywhere and the measurements are more reliable (Figure $6(\mathrm{~d}, \mathrm{e})$ ). As the jet evolves it grows more in the minor axis than the major axis direction. This leads to an almost round jet around $\mathrm{x} / \mathrm{h}=35$. However, the data do not indicate any axes switching up to $\mathrm{x} / \mathrm{h}=35\left(\mathrm{x} / \mathrm{D}_{\mathrm{e}}=\right.$ 10). In this connection it is important to note that for a nozzle with an aspect ratio of around 3 Gutmark et al. ${ }^{9}$ observed axes switching around $\mathrm{x} / \mathrm{D}_{\mathrm{c}}=2.5(\mathrm{x} / \mathrm{h} \sim$ 5). Krothapalli et al. ${ }^{8}$ used a nozzle with an aspect ratio of 16.66 and deduced their apparent axis switching location to be around an $x / D_{c}$ of 30 . Therefore, for nozzle used in the present work (aspect ratio $=9.63$ ), the switching location could be beyond the region covered by Figure 6 . The present paper, however, will focus on events very close to the nozzle exit.

\subsection{Outer/Inner Parts of the Screech Loop}

This section discusses measurements made using a pair of microphones on either side of the nozzle as well as measurements made using hot-films in the shear layers on both sides of the rectangular jet. Figure 7(a) shows a power spectrum obtained using a microphone located at the nozzle exit. Another microphone was located on the other side of the smaller dimension, h, of the nozzle. Figures 7(b) and 7 (c) represent the coherence and the cross-spectrum phase between the two microphones on either side of the jet. In the microphone power spectrum three distinct peaks are observed. The screech frequency (f), and its harmonics (2f, 3f). The coherence function is nearly equal to 1 at the three peaks indicating that the 2 signals are highly phase correlated. The cross-spectrum phase is an indication of the average phase difference between the two microphones. This phase difference is about $\pi$ for $\mathrm{f}$, 0 for $2 f$ and $\pi$ again for $3 f$. This indicates that $f$ and $3 \mathrm{f}$ are flapping (sinuous) modes while $2 \mathrm{f}$ is a nonflapping (varicose) mode.

It is essential to note that the rectangular jet does not have the symmetry of the circular jet that permits the rigorous Fourier decomposition of a measured disturbance into its azimuthal components. However, it is possible to classify a hydrodynamic instability mode excited by screech as being symmetric or antisymmetric, or as a combination of both types of modes. The interpretation of these results is discussed in the next section.

Figure 8 shows the same type of data as Figure 7, however, the data was taken using a pair of hot-films located on either side of the jet at probe immersions yielding a steady flow Mach number of 0.4. The observations that can be made from Figure 8 are similar to the ones made from Figure 7. It should be pointed out that Figures(7) and (8) represent measurements in both parts of the loop that produces and sustains screech. The inner part of the screech loop is represented by the hot-wire measurements (Figure(8)) of the hydrodynamic instability modes. The outer part of the screech loop is represented by the microphone measurements (Figure(7)) near the nozzle lip. This is the component that has propagated upstream (feedback) to the nozzle lip. The trends observed in Figures 7 and 8 for a $\mathrm{M}_{\mathrm{j}}=1.44$ jet were also observed at other Mach numbers $\left(\mathrm{M}_{\mathrm{j}}=1.25\right.$, 1.55). However, the data are not reproduced here in the interest of conciseness.

\subsection{Evolution of Coherent Instability Modes in the Shear Layer}

For the data presented in Figure 9, two single hotfilms were placed on opposite sides of the jet centerline. One probe was fixed at $\mathrm{x} / \mathrm{h}=1.76$ at the $\mathrm{M}=0.4$ location. The other probe was moved in the opposite shear layer from $\mathrm{x} / \mathrm{h}=1.76$ to $\mathrm{x} / \mathrm{h}=10$ along the $M=0.4$ line. The variation of the $M=0.4$ location with downstream distance is shown in Figure 9(a). The shock locations are also shown in the 
figure. The transverse location of the $\mathrm{M}=0.4$ location is seen to dip at the shock locations. Figure 9(b) shows the amplification of the three modes ( $f$ ), (2f) and (3f) versus axial distance along the $M=0.4$ curve described in Figure 9(a). The linear spectral coherence is plotted for various positions of the movable probe in Figure 9(c). For the (f) mode the coherence is almost 1 for the entire distance traversed. This indicates that the origin of the upstream fluctuations is attributed to a strong feedback from the coherent structure downstream. Had the feedback not been so strong, one would not have expected a high coherence. The high coherence also indicates that the $\tilde{\mathrm{u}}_{\mathrm{f}}$ fluctuations at each of the downstream locations are highly correlated with the near nozzle exit flowfield. Similar observations have been made by Thomas and Prakash $^{29}$ for a subsonic planar jet.

For the (2f) mode the coherence is initially high followed by a decrease and a subsequent increase to very high levels between $\mathrm{x} / \mathrm{h}=6$ and 10 . This suggests that the $\tilde{\mathrm{u}}_{2 \mathrm{f}}$ fluctuations at localized downstream flow locations for the harmonic are highly correlated to the near nozzle exit flowfield. At the present time it is not clear why the $(3 \mathrm{f})$ mode displays a low coherence for the entire axial distance traversed.

\subsection{Mutual Interaction of Coherent Instability Modes}

Since several dominant modes exist, it is necessary to look for significant mutual interactions which could be caused by resonance. Therefore, for the identifiable modes the axial wavenumber and phase velocity were measured. The information was obtained using hot-film probes. The hot-film probe was moved axially along the $\mathrm{M}=0.4$ line and referenced to a fixed upstream probe. The screech tone provided a phase reference for the instability wavelength measurement. The average wavelength $(\lambda)$ and the frequency (f) of the screech tone were measured and the phase velocity (c) was calculated $(c=f \lambda)$. Figure 10 shows the evolution of relative phase along the streamwise direction. The physical interpretation of the modes is shown as an inset to Figure 10.

The phase velocities of the screech mode and its harmonics obtained from Figure 10 are given in Table II.
The axial wavenumber $\left(\alpha_{x}=\frac{2 \pi}{\lambda}\right)$ and the frequency parameter ( $\omega=2 \pi f)$, along with values of $c / U_{j}$ and c/a, are shown in Table II. From Table II it can be seen that

$$
\begin{gathered}
\left(\alpha_{I}\right)_{2}=2\left(\alpha_{I}\right)_{1} \\
\omega_{2}=2 \omega_{1} \quad\left(f_{2}=2 f_{1}\right)
\end{gathered}
$$

Therefore

$$
\left(C / U_{j}\right)_{2}=\left(C / U_{j}\right)_{1}
$$

where the subscripts 1 and 2 denote modes (f) and (2f). Thus the conditions for resonance are satisfied for the resonant interaction of $f$ and $2 f$. Stuart and DiPrima ${ }^{30}$ have studied such resonant interactions in Stokes waves.

The nonlinear interaction of instability modes in a cylinder wake was experimentally studied by Mansy and Williams. ${ }^{31}$ They found that for resonant mode interactions the interacting modes would have to follow a set of symmetry rules. They summarized the rules as: (1) antisymmetric and symmetric modes will interact to produce antisymmetric modes. (2) antisymmetric interacting with antisymmetric or symmetric interacting with symmetric will produce symmetric modes.

In the present experiment three dominant modes $f, 2 f$ and $3 \mathrm{f}$ were observed. The harmonics could be considered as being the product of simple two mode sum or difference interactions.

$$
\begin{aligned}
f_{a}+f_{a} & =2 f_{s} \\
f_{a}+2 f_{s} & =3 f_{a} \\
3 f_{a}-2 f_{s} & =f_{a} \\
2 f_{s}-f_{a} & =f_{a}
\end{aligned}
$$

Where the subscripts "a" and "s" denote the antisymmetric and symmetric modes respectively. Therefore, the interaction of the screech mode with itself and its harmonics is consistent with the experimentally derived symmetry rules $^{31}$ and the theory of Chow. ${ }^{32,33}$ 


\subsection{Evolution of Spanwise Instability Modes}

Detailed measurements were made in the $\mathrm{xz}$ plane on the $\mathrm{M}=0.4$ surface of the rectangular jet with a fully expanded Mach number of 1.44. Figure 11(a) shows the constant Mach number surface. The axial extent of the measurements ranged from $\mathrm{x} / \mathrm{h}=1.76$ to 10 , and was sufficient to include 4 shocks ( 2.5 screech wavelengths). The spanwise extent of the measurements ranged from $\mathrm{z} / \mathrm{h}=-4$ to +4 . Figure 11(b) shows the phase averaged coherent velocities at the screech tone frequency on the $\mathrm{U} / \mathrm{U}_{\mathrm{j}}=0.4$ surface. Three islands of $\tilde{u}_{\mathrm{p}} \mathrm{U}_{0.4}$ peaks of $0.14,0.167$ and 0.17 were observed. The islands appear to be straddled by the shocks. The peaks were observed to be near the $\mathrm{z} / \mathrm{h}=0$ line (jet center). There is a considerable drop in the value of $\tilde{u}_{\mathrm{f}} / \mathrm{U}_{0.4}$ downstream of the shocks. The shock and nearfield noise locations are shown in Figure 11(b). The work of Rice and Taghavi ${ }^{10}$ described the nearfield screech noise source structure. They observed 5 distinct islands of maximum screech noise. These sources were located just downstream of the 5 observable shocks, and are shown in the figure along with the shock locations.

Figure 11(c) shows the variation of the phase difference on the $M=0.4$ surface. The relative phase was obtained by keeping one hot-film probe fixed at $\mathrm{z} / \mathrm{h}=0, \mathrm{x} / \mathrm{h}=1.76$ and moving the second probe over the entire $x z$ plane (on the $M=0.4$ surface). The figure represents a view of the hydrodynamic instability phase fronts on the $M=0.4$ surface. The contours in Figure 11(c) represent an increasing relative phase with a contour spacing of 10 degrees. It should be noted that irregularities exist near the edges and in addition significant spanwise variations in the phase are observed around $\mathrm{x} / \mathrm{h}=8$.

\subsection{Noise Radiated by the Coherent Instability Modes.}

Figure $12(a, b)$ shows the nearfield coherent sound pressure levels measured on the xy (minor axis plane) and $\mathrm{xz}$ (major axis plane) planes for both the screech tone(12(a)) and its harmonic (12(b)). The very nearfield, i.e. , the region where the acoustic field is contaminated by the potential fluctuations associated with the hydrodynamic waves, has been avoided. Based on the contours, one can draw general inferences about the direction of propagation of the screech tone and its harmonic. In both planes the screech tone can be inferred to propagate mainly upstream. In addition there appear to be a small amount of propagation in the normal and downstream directions.

The acoustic phase fronts shown in Figure $13(a, b)$, however, provide a clear indication of the direction of propagation. It is important to note that the normal to the acoustic phase fronts indicates the direction of propagation of the acoustic waves in the nearfield. It is also very clear that the acoustic phase fronts at the screech tone frequency are out-of-phase on either side of the jet whereas those for its harmonic are symmetric on either side of the jet. This is consistent with measured coherent velocity disturbances in the shear layer being antisymmetric for the screech tone and symmetric for the harmonic of the screech tone. The observations that can be made from Figure $12(\mathrm{a}, \mathrm{b})$ and $13(\mathrm{a}, \mathrm{b})$ are consistent with the expressions derived by Powell ${ }^{1}$ for the propagation lobe shapes for the fundamental screech frequency and its harmonic. He showed that the fundamental screech tone propagates upstream in a narrow lobe. The harmonic, on the other hand, propagates in a direction normal to the jet axis. The experimental observations of the present work seem to closely match Powell's ${ }^{1}$ predictions based on his assumption of 4 rather than 3 screech noise sources.

It should be noted that the present work focuses only on the screech tone and its harmonic as well as its relationship to the coherent structure of the jet. It is recognized that there are other types of noise such as jet and shock associated broadband noise which are also linked to the evolution of the coherent structures. The present work does not attempt to address the above.

\subsection{Azimuthal Directivity of the Screech Tone and its Harmonic}

Figure $14(a, b)$ shows the polar directivity plots of the screech tone and it harmonic in the yz plane (see Figure 1(a)) at the jet exit. The azimuthal angle $\theta$ is defined in Figure 1(b). The magnitudes of the tones are shown in Figure 14(a) and the corresponding relative phase is shown in Figure 14(b). The measurements were made by moving a microphone along a circular arc with a radius of $r / h=7$. For the relative phase measurements the moving microphone was referenced to a fixed microphone. It needs to be 
emphasized that the azimuthal directivity is measured here on the yz plane as opposed to the more usual documentation of the polar directivity on the $\mathrm{xz}$ or $\mathrm{xy}$ planes. Therefore for these measurements the jet exits out of the plane of the figure. The sound pressure levels on either side display a remarkable symmetry (Figure 14(a)) and the phase plot (Figure 14(b)) shows the phase variation for the screech tone from 0 to 180 degrees. In contrast the harmonic of the screech tone has a phase difference of about 0 degrees all around the jet.

\section{CONCLUDING REMARKS}

Hydrodynamic instability modes excited by screech tones were studied in a rectangular underexpanded jet. The screech modes in the acoustic measurements made outside the jet (outer loop) were also observed in the coherent instability wave measurements in the shear layer (inner loop). Three dominant harmonically related instability modes were observed. The hydrodynamic instability modes observed in the shear layer at the screech frequency were seen to occur in the antisymmetric (sinuous) mode. The first and second harmonics were found to occur in the symmetric (varicose) and antisymmetric (sinuous) modes respectively. The dominant instability modes satisfied the conditions for resonance. It was possible to explain the mutual interaction of the instability modes using a set of previously derived symmetry rules. From a two dimensional map of the coherent wave evolution in the streamwise and spanwise directions strong three dimensionalities were observed beyond $\mathrm{x} / \mathrm{h}=8$. The nearfield noise measurements indicated that the screech tone was directed to the jet lip (feedback) whereas its harmonic was directed in a direction normal to the jet flow. The acoustic phase fronts in the nearfield were antisymmetric for the screech tone and symmetric for its harmonic.

\section{ACKNOWLEDGEMENTS}

The authors would like to thank the following individuals for their constructive comments and suggestions: Prof. D.K. McLaughlin, Prof. P.J. Morris, Prof. C.K.W. Tam, Prof. J.T. Stuart, Dr. K.K. Ahuja, Dr. R.R. Mankbadi, and Dr. K.B.M.Q. Zaman.

\section{REFERENCES}

1. Powell, A., "On the Noise Emanating from a Two-Dimensional Jet above the Critical Pressure," The Aeronautical Quarterly, Vol. IV, 1953, pp. 103-122.

2. Davies, M.G., and Oldfield, D.E.S., "Tones from a Choked Axisymmetric Jet. I Cell Structure, Eddy Velocity and Source Locations," Acustica, Vol. 12, No. 4, 1962, pp. 257-266.

3. Davies, M.G., and Oldfield, D.E.S., "Tones from a Choked Axisymmetric Jet. II. The Self Excited Loop and Mode of Oscillation," Acustica, Vol. 12, No. 4, 1962, pp. 267-277.

4. Morkovin, M.V., "Critical Evaluation of Transition from Laminar to Turbulent Shear Layers with Emphasis on Hypersonically Traveling Bodies," AFFDL-TR-68-149, 1969.

5. Rogler, H.L., and Reshotko, E., "Disturbances in a Boundary Layer Introduced by a Low Intensity Array of Vortices," SIAM J. Appl. Math. Vol. 28, 1975.

6. Hammitt, A.G., "The Oscillation and Noise of an Overpressure Sonic Jet," J. Aerospace Sci., Vol. 8, No. 9, 1961, pp. $673-680$.

7. Glass, D.R., "Effects of Acoustic Feedback on the Spread and Decay of Supersonic Jets," AIAA J., Vol. 6, 1968, pp. 1890-1897.

8. Krothapalli, A., Hsia, Y., Baganoff, D., and Karamcheti, K., "The Role of Screech Tones in Mixing of an Underexpanded Rectangular Jet," Journal of Sound and Vibration, Vol. 106, 1986, pp. 119-143.

9. Gutmark, E., Schadow, K.C., and Bicker, C.J., "On the Near Acoustic Field and Shock Structure of Rectangular Supersonic Jets," ALAA paper 89 -1053, 1989.

10. Rice, E.J., and Taghavi, R., "Screech Noise Source Structure of a Supersonic Rectangular Jet," AIAA Paper 92-0503, 1992.

11. Seiner, J.M., "Advances in High Speed Jet Aeroacoustics," AIAA Paper 84-2275, 1984.

12. Morrison, G.L., and McLaughlin, D.K., "Instability Process in Low Reynolds Number Supersonic Jets," AIAA J., Vol. 18, 1980, pp. 793-800.

13. Lepicovsky, J., Ahuja, K.K., Brown, W.H., and 
Multiple Pages Missing from Available Version 


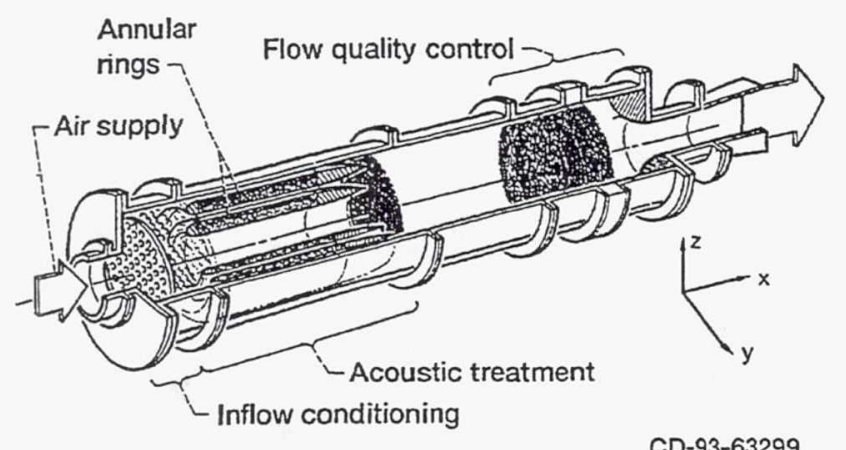

(a) Schematic of supersonic jet facility.

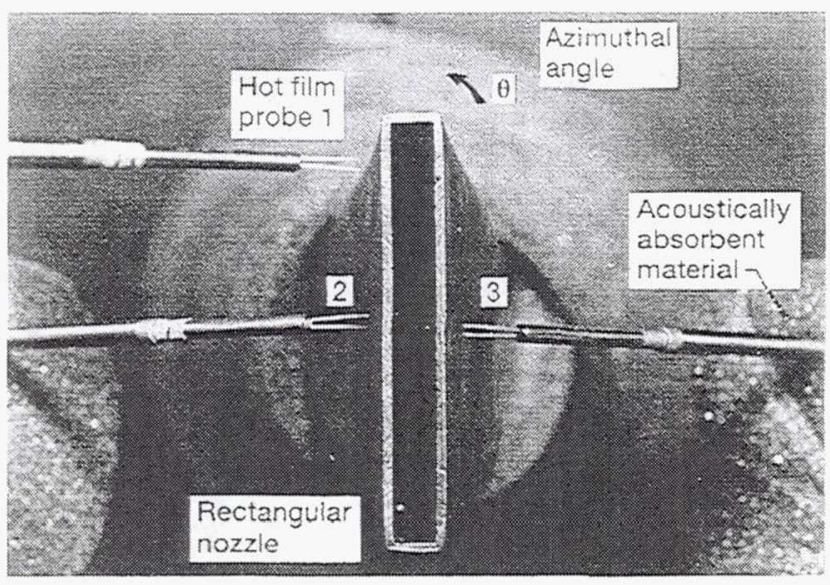

(b) Rectangular nozzle and hot-wire measurement set-up.

Figure 1.-Experimental set-up.

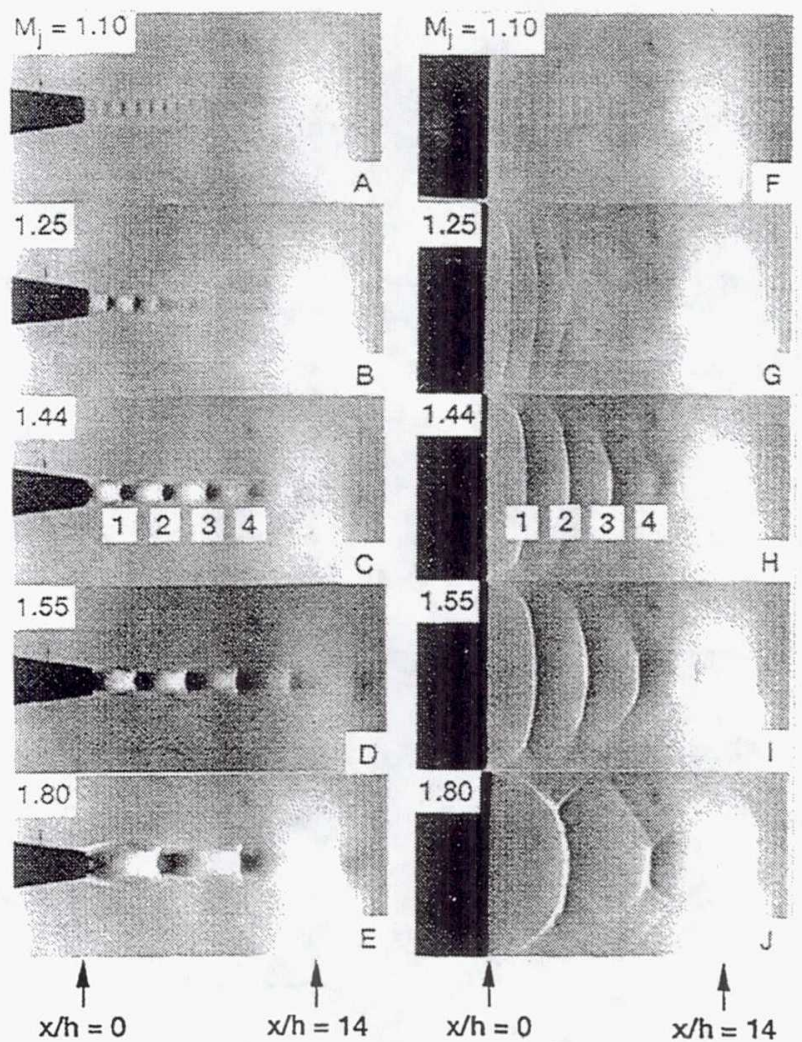

Figure 2.-Focusing Schlieren photographs of the shock-cell structure of an underexpanded rectangular jet. 


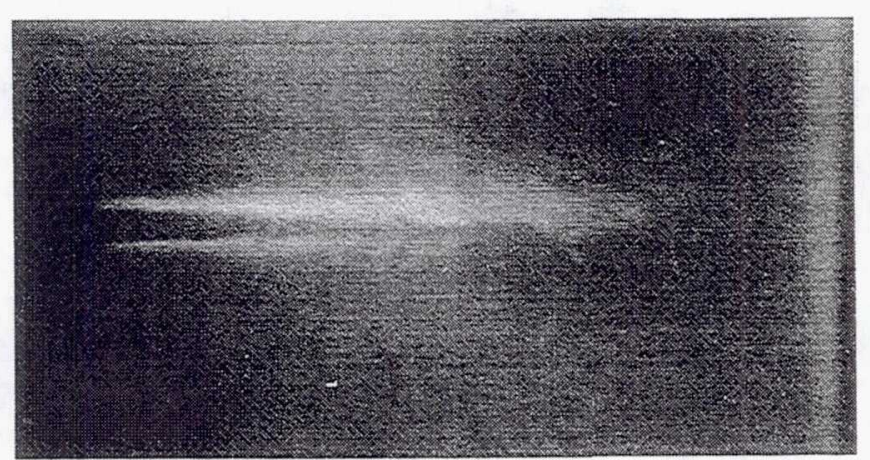

(a) $M_{j}=1.1$.

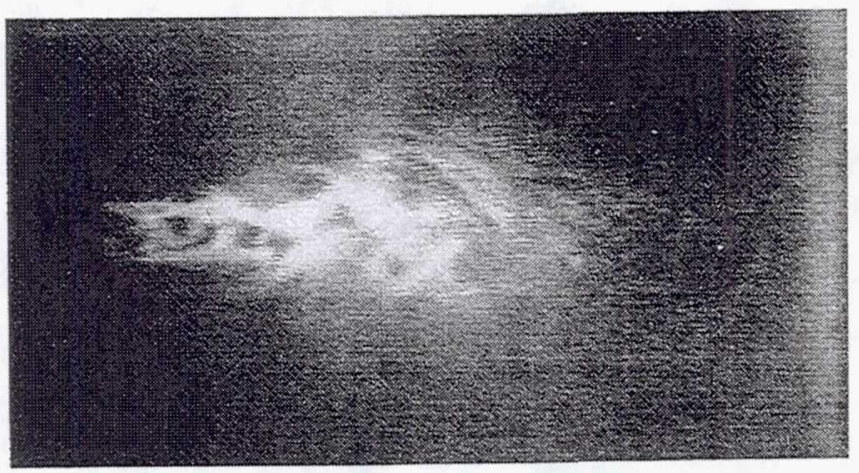

(b) $M_{j}=1.25$.

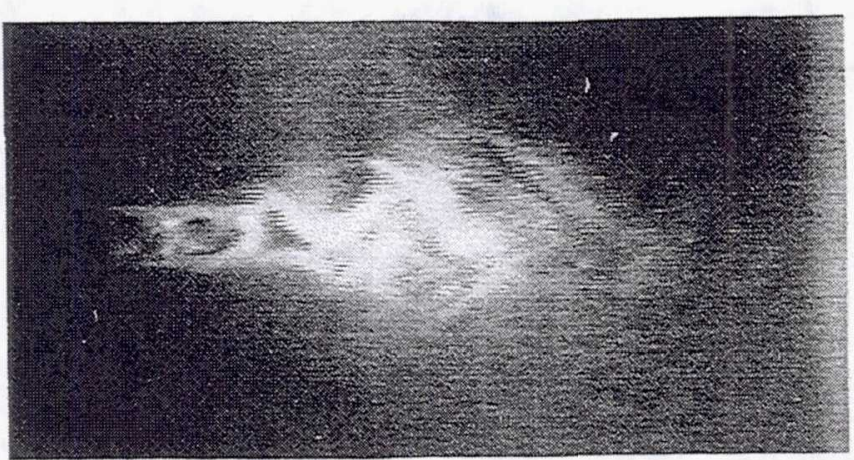

(c) $M_{j}=1.35$.

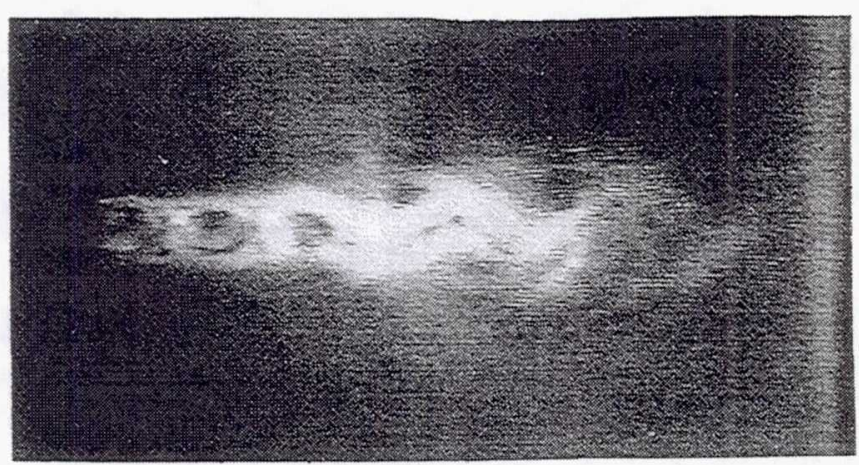

(d) $M_{j}=1.44$.

Figure 3.-Strobed Schlieren photographs of underexpanded rectangular jets.

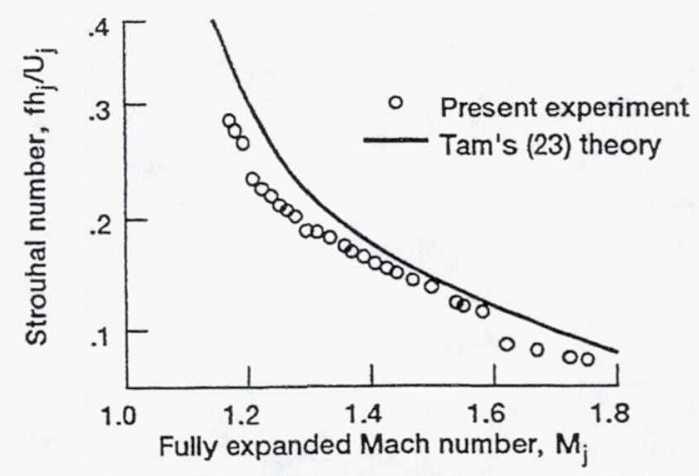

(a) Screech Strouhal number versus fully expanded Mach number.

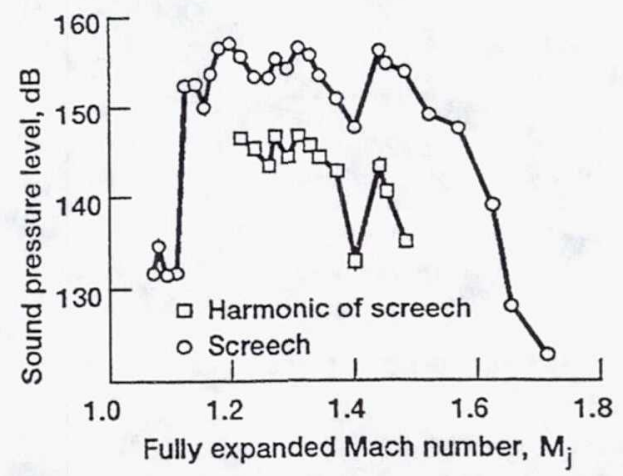

(b) Screech sound pressure level versus fully expanded Mach number.

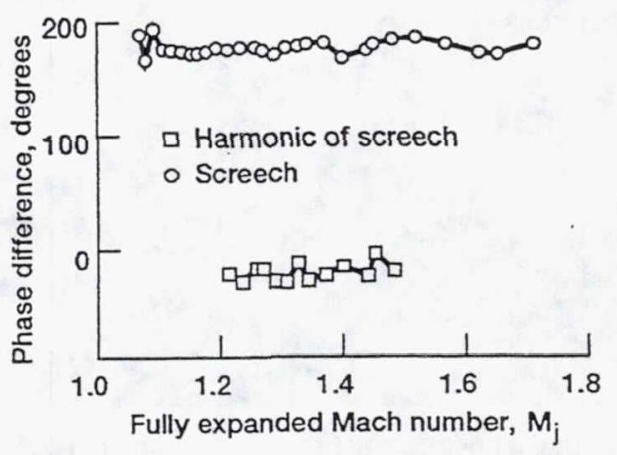

(c) Phase difference between microphones on either side of the jet versus fully expanded Mach number.

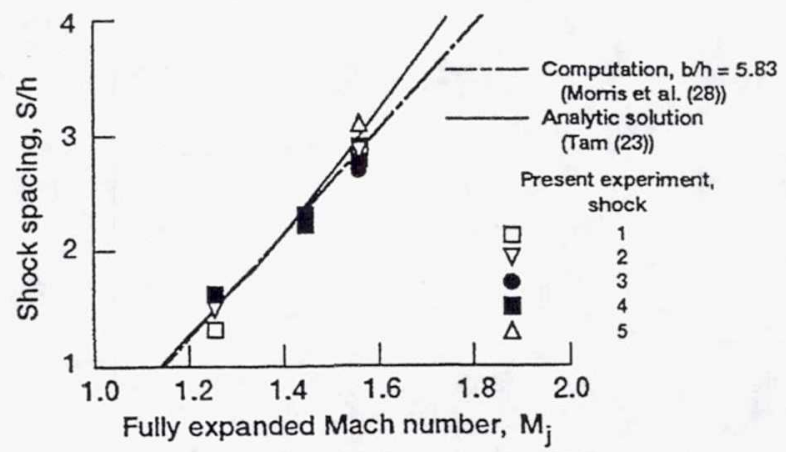

(d) Shock spacing versus fully expanded Mach number.

Figure 4.-Screech tone characteristics of a rectangular jet. 


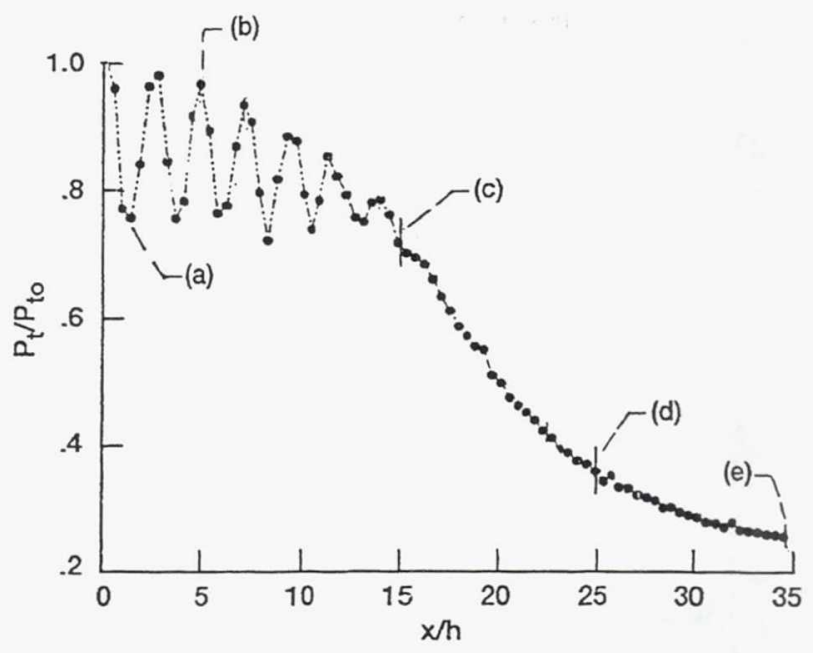

Figure 5.-Axial variation of normalized total pressures on the jet centerline (cross-sections of locations marked a-e are described in Figure 6(a-e)).

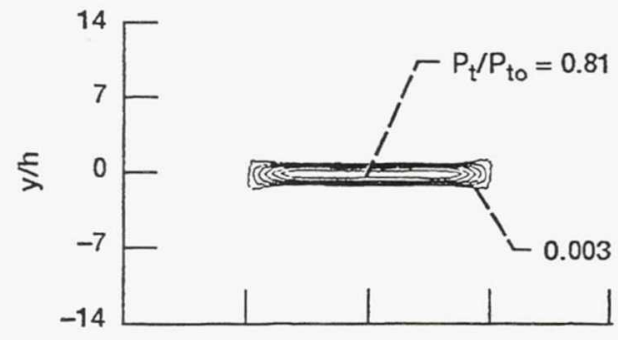

(a) $x / \mathrm{h}=1$.

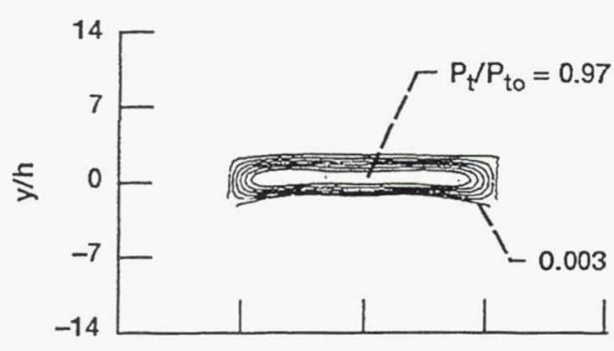

(b) $\mathrm{x} / \mathrm{h}=5$.

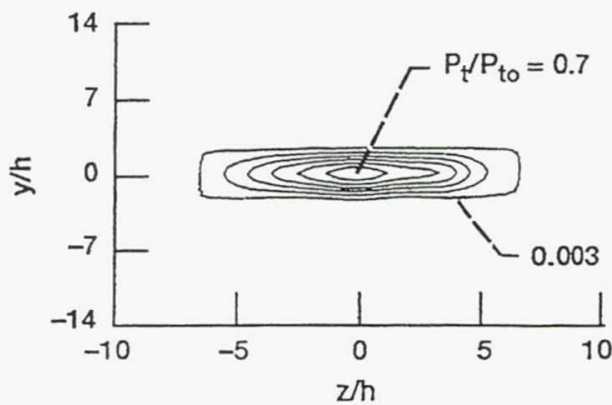

(c) $x / \mathrm{h}=15$.

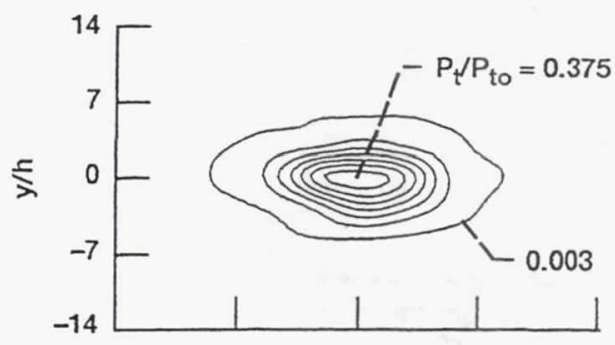

(d) $x / h=25$.

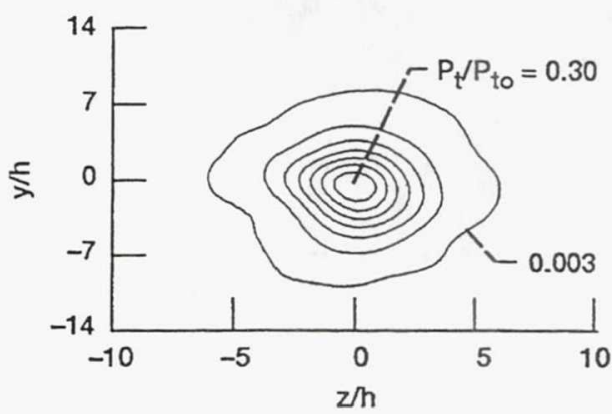

(e) $x / h=35$.

Figure 6.-Contours of normalized total pressure at various axial stations. 


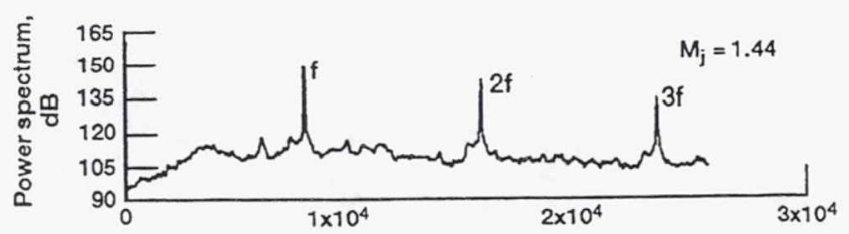

(a) Power spectrum.

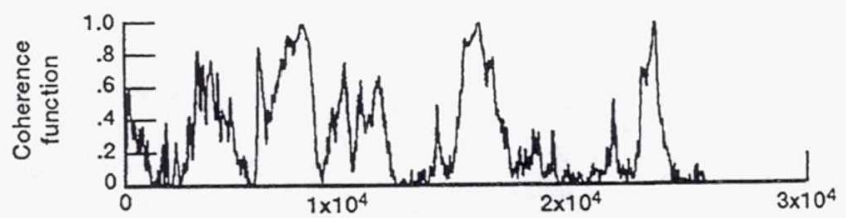

(b) Linear spectral coherence function.

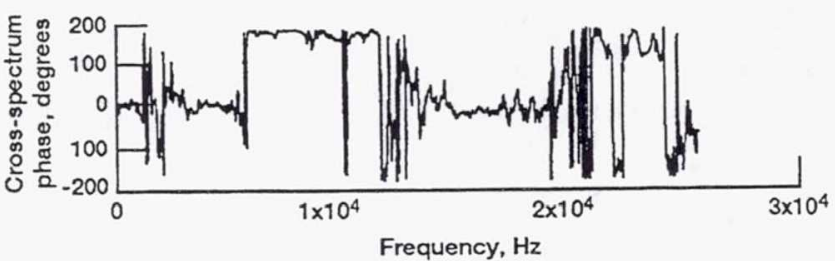

(c) Cross-spectrum, phase, degrees.

Figure 7.-Cross-correlations of the screech tone at the nozzle lip obtained using two microphones on either side of the nozzle.

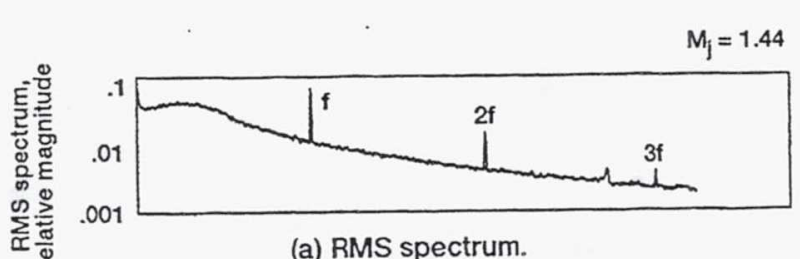

(a) RMS spectrum.

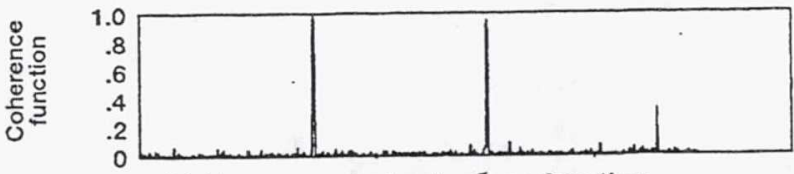

(b) Linear spectral coherénce function.

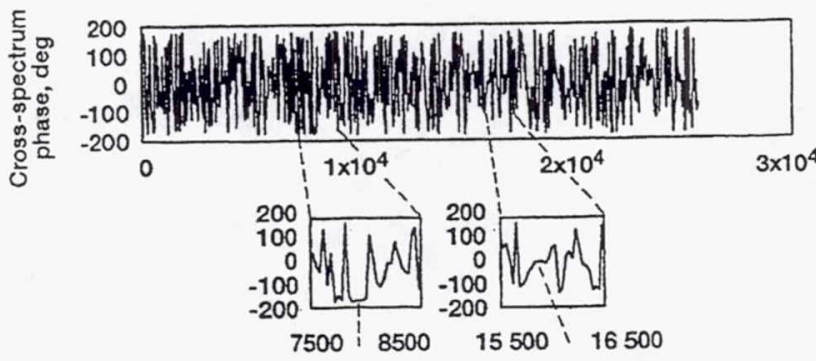

(c) Cross-spectrum phase.

Figure 8.-Cross-correlations of the instability modes in the shear layer obtained using two hot-films on either side of the jet measured at $\mathrm{x} / \mathrm{h}=1.76, \mathrm{z} / \mathrm{h}=0$, with both probes at the $\mathrm{M}=0.4$ location.

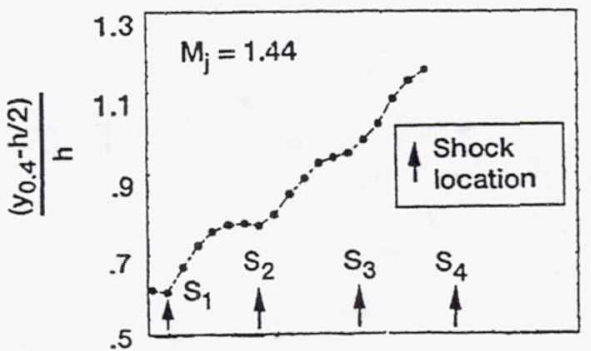

(a) Definition of the $M=0.4$ line in the shear layer.

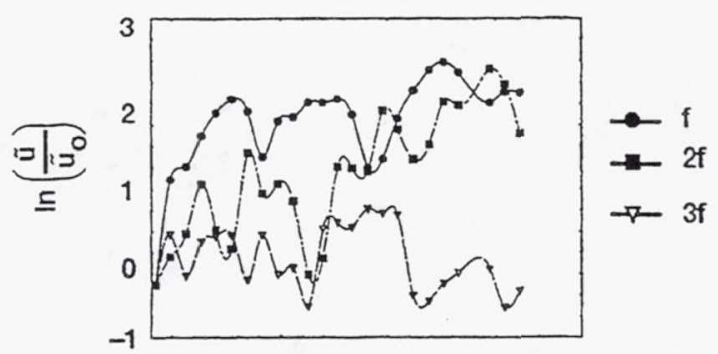

(b) Axial evolution of the coherent modes.

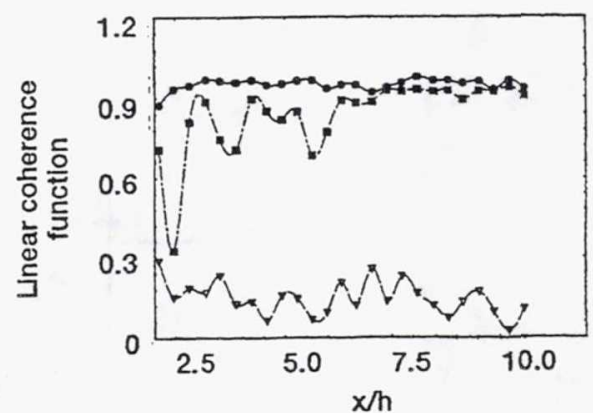

(c) Axial evolution of the linear spectral coherence function.

Figure 9.-Evolution of instability modes in the shear layer along the $M=0.4$ line, $(z / h=0)$.

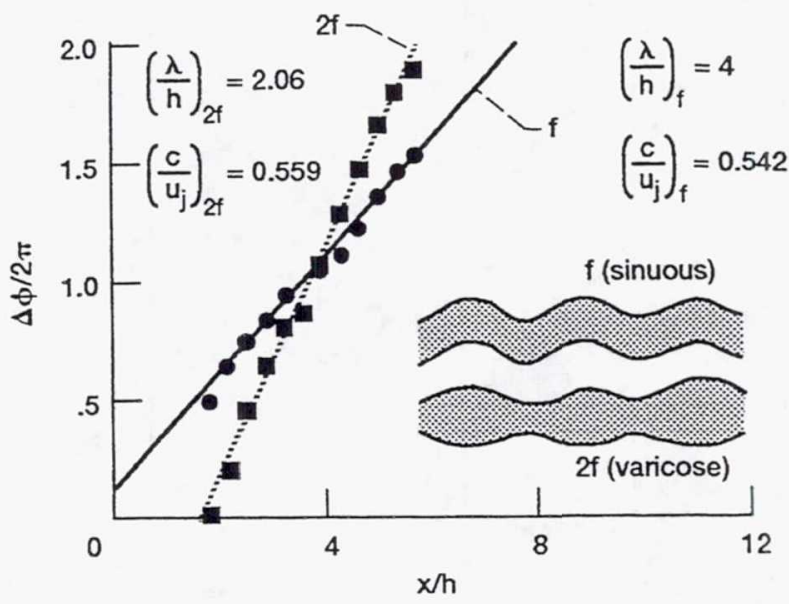

Figure 10.-Variation of the phase of the coherent modes with axial distance along the $M=0.4$ line $(z / h=0)$. 


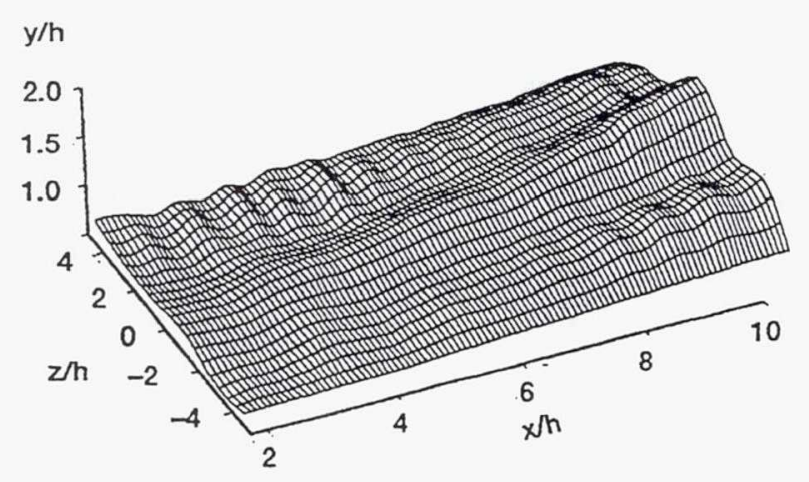

(a) Definition of the $M=0.4$ surface in the shear layer.

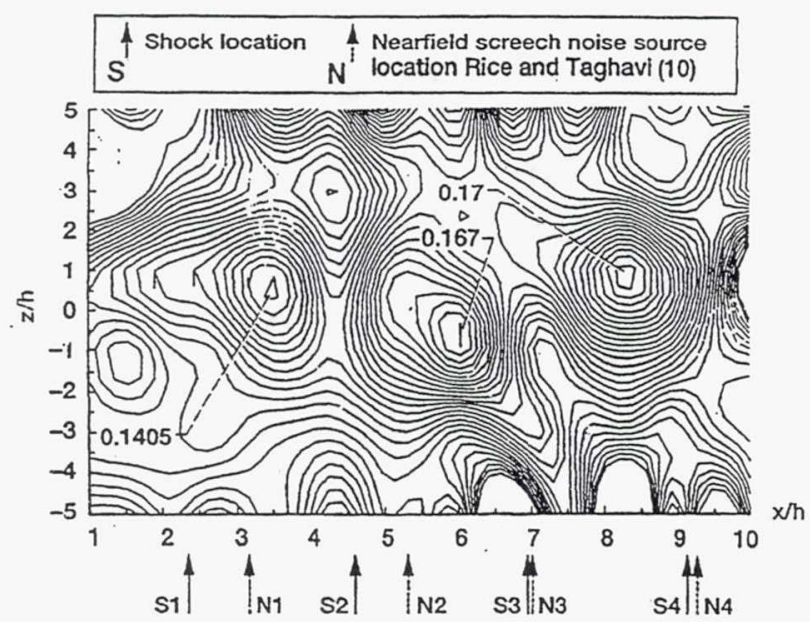

(b) Iso-magnitude $\left(\tilde{u}_{f}\right)$ contours of the screech instability mode (peak values are indicated on the figure, contour spacing of $\left.0.01 \tilde{u}_{f} / U_{0.4}\right)$.

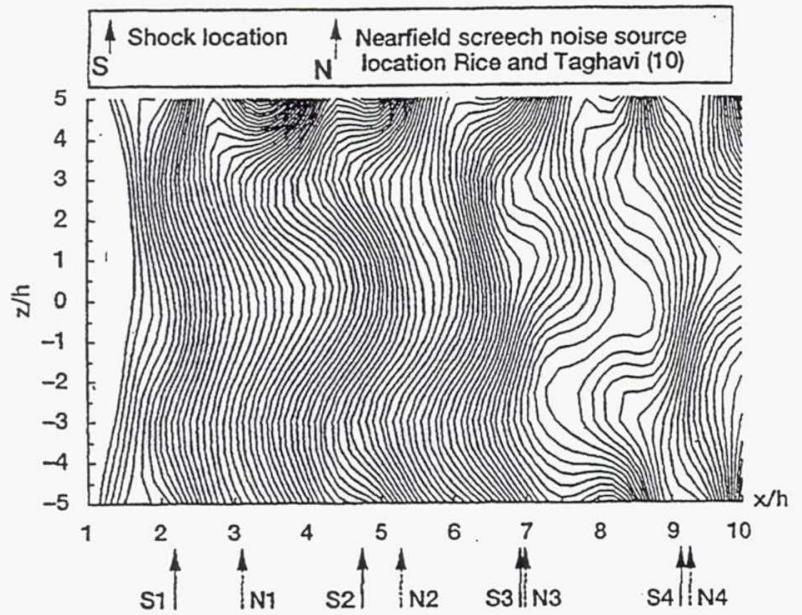

(c) Iso-phase contours of the screech instability mode (increasing relative phase with a contour spacing of 10 degrees).

Figure 11.-Evolution of coherent spanwise modes on the $M=0.4$ surface.

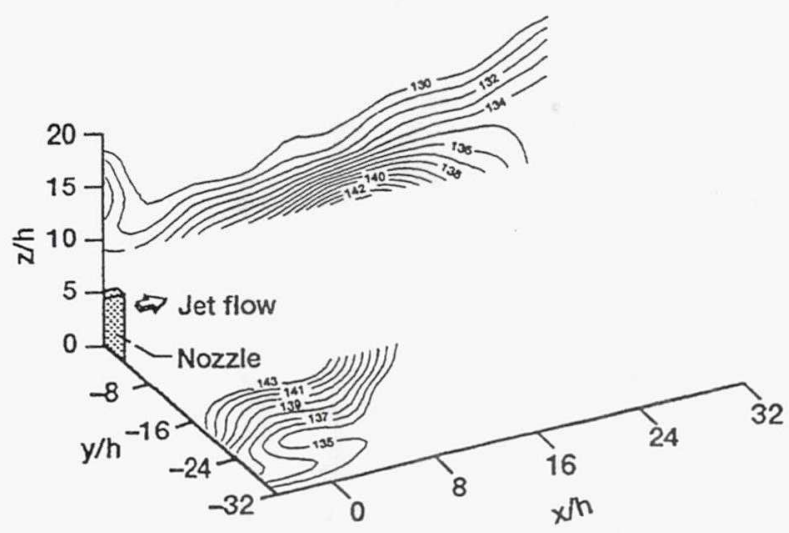

(a) Sound pressure levels coherent at the screech frequency (f).

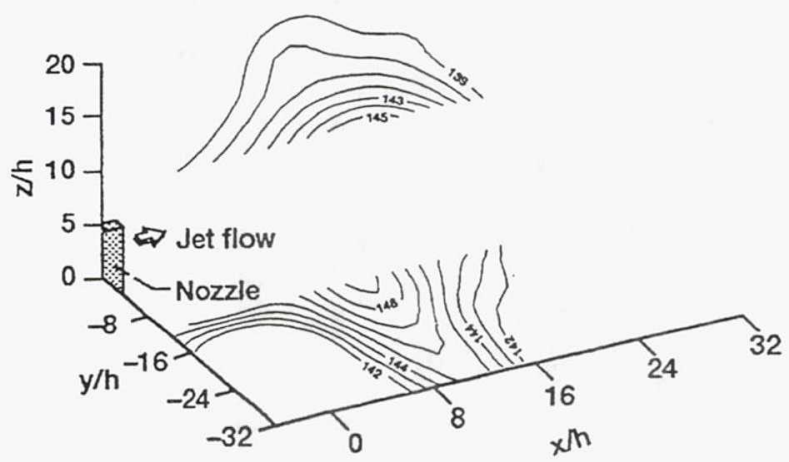

(b) Sound pressure levels coherent at the harmonic of the screech frequency (2f).

Figure 12.-Nearfield noise map of coherent sound pressure levels.

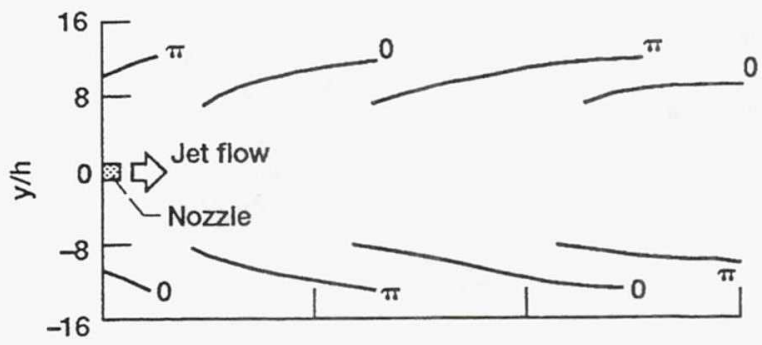

(a) Phase fronts propagating at the screech frequency (f).

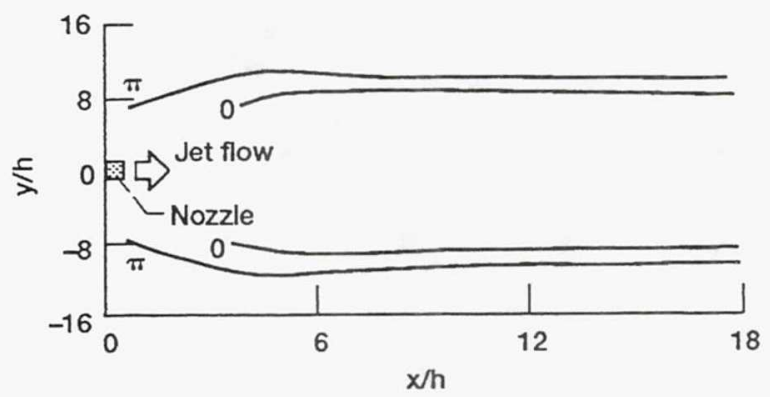

(b) Phase fronts propagating at the harmonic of screech frequency (2f).

Figure 13.-Acoustic phase fronts in the nearfield on either side of the jet. 


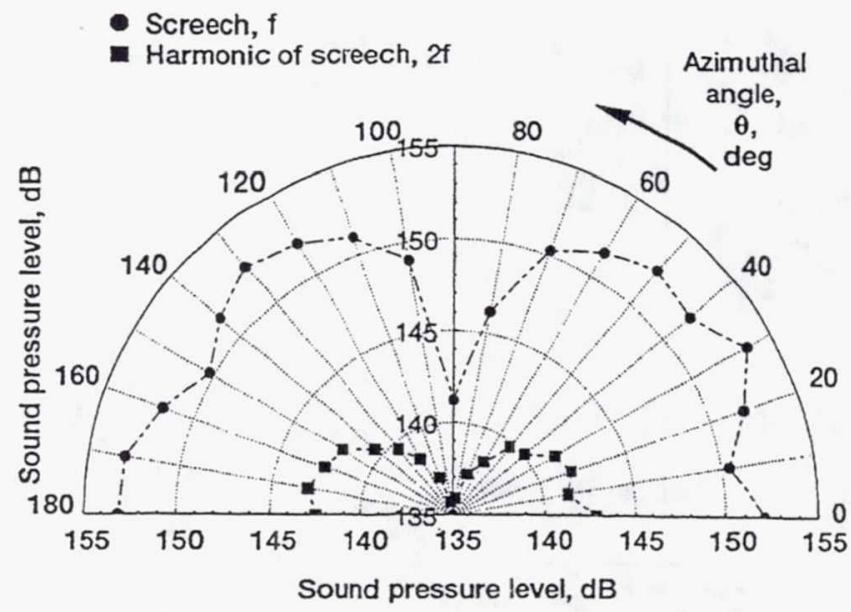

(a) Azimuthal variation of coherent sound pressure levels.

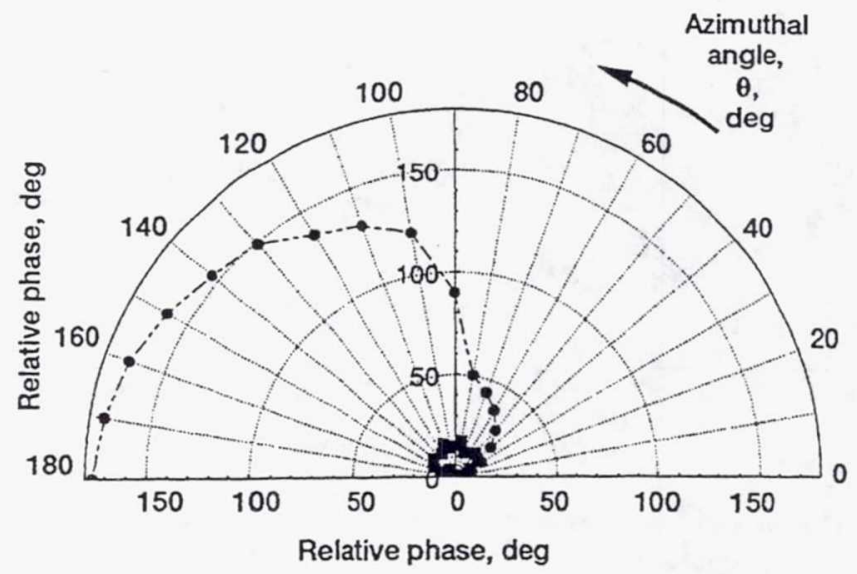

(b) Azimuthal variation of relative phase.

Figure 14.-Azimuthal directivity of the screech tone and its harmonic (measured on an arc with radius $\mathrm{r} / \mathrm{h}=7$ ). 
Public reporting burden for this collection of information is estimated to average 1 hour per response, including the time for reviewing instructions, searching existing data sources, gathering and maintaining the data needed, and completing and reviewing the collection of information. Send comments regarding this burden estimate or any other aspect of this Davis Highway, Suite 1204. Arlington, VA 22202-4302, and to the Office of Management and Budget. Paperwork Reduction Project (0704-0188), Washington, DC 20503.

\begin{tabular}{|l|l|l|}
\hline 1. AGENCY USE ONLY (Leave blank) & $\begin{array}{c}\text { 2. REPORT DATE } \\
\text { December } 1993\end{array}$ & $\begin{array}{r}\text { 3. REPORT TYPE AND DATES COVERED } \\
\text { Technical Memorandum }\end{array}$ \\
\hline
\end{tabular}

\section{TITLE AND SUBTITLE}

5. FUNDING NUMBERS

Instability Modes Excited by Natural Screech Tones in a Supersonic

Rectangular Jet

6. $\operatorname{AUTHOR(S)}$

WU-505-62-52

Ganesh Raman and Edward J. Rice

7. PERFORMING ORGANIZATION NAME(S) AND ADDRESS(ES)

National Aeronautics and Space Administration

Lewis Research Center

Cleveland, Ohio 44135-3191

PERFORMING ORGANIZATION REPORT NUMBER

E-8246

9. SPONSORING/MONITORING AGENCY NAME(S) AND ADDRESS(ES)

10. SPONSORING/MONITORING

AGENCY REPORT NUMBER

National Aeronautics and Space Administration

Washington, D.C. 20546-0001

NASA TM-106409

AIAA-93-4321

11. SUPPLEMENTARY NOTES

Prepared for the 15th AIAA Aeroacoustics Conference, sponsored by the American Institute of Aeronautics and Astronautics, Long Beach, Califronia, October 25-27, 1993. Ganesh Raman, Sverdrup Technology, Inc., Lewis Research Center Group, 2001 Aerospace Parkway, Brook Park, Ohio 44142, (work funded by NASA contract NAS3-25266); and Edward J. Rice, NASA Lewis Research Center. Responsible person, Edward J. Rice, (216) 433-3607.

12a. DISTRIBUTION/AVAILABILITY STATEMENT

12b. DISTRIBUTION CODE

Unclassified -Unlimited

Subject Category 02

13. ABSTRACT (Maximum 200 words)

The evolution of hydrodynamic instability modes self-excited by harmonically related natural screech tones was experimentally investigated. A convergent rectangular nozzle with an aspect ratio of 9.63 was used to produce a supersonic shock containing jet. Measurements in the flow-field were made using standard hot-film probes positioned only in the subsonic (outer) portions of the flow. The hydrodynamic instability mode observed in the shear layer at the screech frequency was observed to be antisymmetric (sinuous) about the smaller dimension of the jet, whereas its harmonic was observed to be symmetric (varicose). In addition the nearfield noise measurements indicated that the radiated screech tone noise was out-of-phase on either side of the small jet dimension whereas its harmonic was inphase over the same region. To our knowledge such an observation on the nature of the harmonic has thus far gone unreported and therefore, is the focus of the present work. The hydrodynamic instability modes occurring at the screech frequency and its harmonic satisfied the conditions for resonance. Detailed measurements of the coherent wave evolution in the streamwise and spanwise directions indicated that strong spanwise variations were present beyond $\mathrm{x} / \mathrm{h}=8$. Details of the screech noise radiated by the coherent instability modes are also presented in this paper.

\section{SUBJECT TERMS}

Rectangular jet; Screech; Supersonic jet; Instability modes; Acoustics; Noise; Hydrodynamic modes; Resonance

\begin{tabular}{|c|c|c|}
\hline $\begin{array}{c}\text { 17. SECURITY CLASSIFICATION } \\
\text { OF REPORT } \\
\begin{array}{c}\text { Unclassified } \\
\text { OF THIS PAGE } \\
\text { Unclassified }\end{array}\end{array}$ & $\begin{array}{c}\text { 18. SECURITY CLASSIFICATION } \\
\text { OFECURITY CLASSIFICATION } \\
\text { OF ABSTRACT } \\
\text { Unclassified }\end{array}$
\end{tabular}




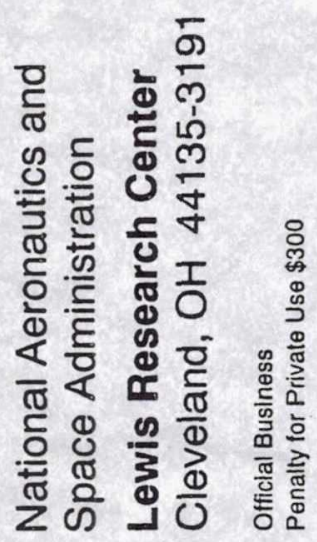

